\title{
QUALIDADE DE UM SOLO SOB DIFERENTES USOS E SOB CERRADO NATIVO(1)
}

\author{
Ricardo Araújo ${ }^{(2)}$, Wenceslau J. Goedert ${ }^{(3)} \&$ Marilusa \\ Pinto Coelho Lacerda ${ }^{(3)}$
}

\begin{abstract}
RESUMO
O uso sustentável do solo tem-se constituído em tema de crescente relevância, em face do aumento das atividades antrópicas. Com o objetivo de avaliar a qualidade do solo em área de Cerrado nativo e em áreas sob diferentes usos, foram amostradas camadas de Latossolo Vermelho-Amarelo sob quatro tipos de ocupação: pastagem natural, pastagem cultivada, cultivo convencional com culturas anuais e florestamento de pínus. As áreas estão localizadas na Fazenda Água Limpa, DF. Foram avaliados os seguintes atributos de qualidade do solo: densidade do solo, resistência mecânica à penetração, taxa de infiltração de água, teor de matéria orgânica, capacidade de troca catiônica, $C$ total da biomassa microbiana e respiração basal. Com base nos dados obtidos, foi organizado um diagrama comparativo e calculado um índice da qualidade do solo para cada tipo de uso. Os resultados evidenciaram relação estreita e inversa entre a qualidade do solo e a intensidade de uso a que as áreas foram submetidas. Mediante análise desses atributos e da elaboração de um modelo comparativo, foi possível avaliar o nível de degradação do solo em função do uso de cada área.
\end{abstract}

Termos de indexação: impactos ambientais, física do solo, química do solo, biologia do solo.

\footnotetext{
(1) Parte da Tese de Mestrado do primeiro autor apresentada à Universidade de Brasília - UnB. Recebido para publicação em outubro de 2004 e aprovado em maio de 2007.

(2) Engenheiro-Agrônomo, Mestre em Ciências Agrárias, Instituto Brasileiro do Meio Ambiente e dos Recursos Naturais Renováveis - IBAMA. SCEN, trecho 2, bloco A, CEP 70818-900 Brasília (DF). E-mail: ricardo.araujo@ibama.gov.br

(3) Professor Adjunto, Faculdade de Agronomia e Medicina Veterinária da Universidade de Brasília - UnB. E-mails: goedert@unb.br; marilusa@unb.br
} 


\title{
SUMMARY: SOIL QUALITY UNDER DIFFERENT USES AND NATIVE CERRADO
}

\begin{abstract}
Sustainable soil use is becoming increasingly relevant given the increase of anthropic activities. In order to evaluate the soil quality, soil samples were collected from five areas: natural Cerrado (reference), native pasture, planted pasture, annual crops under conventional tillage and pine forest. The areas are located in the Federal District, Brazil, in a clayey Red Yellow Latosol (Acrustox). The following soil quality attributes were measured: bulk density, mechanical resistance to penetration, water infiltration rate, organic matter content, cation exchange capacity, carbon of microbial biomass and basal respiration. Based on the obtained data a comparative diagram was drawn and a soil quality index calculated for each type of use. The results showed a close inverse relationship between soil quality and intensity of use to which the areas were submitted. By analyzing these attributes and the establishment of a comparative model it was possible to evaluate the level of soil degradation caused by each type of use in each area.
\end{abstract}

Index terms: environmental impacts, soil physics, soil chemistry, soil biology.

\section{INTRODUÇÃO}

O uso sustentável dos recursos naturais, especialmente do solo e da água, tem-se constituído em tema de crescente relevância, em razão do aumento das atividades antrópicas. Conseqüentemente, cresce a preocupação com o uso sustentável e a qualidade desses recursos.

Segundo Doran \& Parkin (1994), a qualidade do solo (QS) pode ser conceituada como a capacidade de esse recurso exercer várias funções, dentro dos limites do uso da terra e do ecossistema, para sustentar a produtividade biológica, manter ou melhorar a qualidade ambiental e contribuir para a saúde das plantas, dos animais e humana. Um dos desafios atuais da pesquisa é como avaliar a qualidade de um solo de maneira simples e confiável. Segundo esses autores, ela pode ser medida por meio da quantificação de alguns atributos, ou seja, de propriedades físicas, químicas e biológicas, que possibilitem o monitoramento de mudanças, a médio e longo prazo, no estado de qualidade desse solo.

Com o objeitvo de facilitar a comparação da qualidade de solos nativos e submetidos a diferentes usos, podem-se estabelecer índices numéricos de QS (similares aos conhecidos índices de salinidade, de erodibilidade, de estabilidade de agregados, entre outros) ou adotar a linha de modelagem, gráfica ou matemática.

O monitoramento da qualidade do solo deve ser orientado para detectar tendências de mudanças que são mensuráveis num período relativamente longo. Esse monitoramento pode ser feito na propriedade agrícola ou em níveis mais abrangentes, como microbacia hidrográfica, região e outros. As práticas de manejo e conservação do solo e da água devem ser planejadas e executadas procurando-se manter ou mesmo melhorar seus atributos, de modo a aumentar a capacidade do solo em sustentar uma produtividade biológica competitiva, sem comprometer a qualidade da água.

O estabelecimento de índices de qualidade do solo é ainda útil na tarefa de avaliação de impactos ambientais quando biomas são incorporados ao processo produtivo, seja de forma extensiva ou intensiva. Torna-se, assim, um instrumento importante nas funções de controle, fiscalização e monitoramento de áreas destinadas à proteção ambiental.

Existem vários modelos para avaliação da QS, conforme descrito por Tótola \& Chaer (2002); entretanto, esses modelos são de complexa aplicação e enfatizam a qualidade do solo voltada para a produção, sendo sua aplicação direcionada sobretudo para a pesquisa. Dessa forma, é necessário que sejam desenvolvidos métodos para avaliação ambiental com aplicação rápida, a fim de que possam ser utilizados por instituições de fiscalização e controle ambiental, como órgãos de meio ambiente, organizações da sociedade civil, peritos e demais profissionais da área.

Dois diferentes enfoques têm sido propostos para se estabelecerem critérios de referência: solo de área sob vegetação natural, por representar as condições ecológicas de estabilidade do ambiente; e parâmetros agronômicos que maximizem a produção e conservem o meio ambiente (Santana \& Bahia Filho, 2002).

Islam \& Weil (2000) propuseram a utilização de dados das características físicas, químicas e biológicas, coletados em solo de uma área de floresta natural não perturbada, como referência para montagem de um índice geral da qualidade do solo.

A hipótese deste estudo é de que há relação inversa entre a intensidade de uso de um solo e uma boa qualidade. $\mathrm{O}$ objetivo deste trabalho foi avaliar, comparativamente, a qualidade do solo, utilizando-se atributos de natureza física, química e biológica, em áreas ou glebas sob diferentes usos. 


\section{MATERIAL E MÉTODOS}

\section{Caracterização das áreas avaliadas}

As áreas ou glebas se localizam na Fazenda Água Limpa, da Universidade de Brasília (UnB), entre as Áreas de Relevante Interesse Ecológico (ARIE) Capetinga e Taquara, Unidades de Conservação Federal geridas pela UnB, Instituto Brasileiro de Geografia e Estatística (IBGE) e Instituto Brasileiro do Meio Ambiente e dos Recursos Naturais Renováveis (IBAMA).

A altitude média na região do estudo varia entre 900 e 1.000 m. Segundo a classificação de Köppen, o clima é Aw (tropical estacional de savana) e se situa entre tropical de savana e temperado chuvoso de inverno seco, com precipitação média de $1.550 \mathrm{~mm}$ anuais. O solo classificado, segundo o Sistema Brasileiro de Classificação de Solos (Embrapa, 1999), é um Latossolo Vermelho-Amarelo distrófico típico A moderado textura muito argilosa fase Cerrado tropical subcaducifólio relevo plano.

A qualidade do solo foi avaliada em cinco áreas amostrais, todas com declividade em torno de $5 \% \mathrm{e}$ distância máxima entre elas de $1.500 \mathrm{~m}$, cujo uso pode ser assim caracterizado: (a) Cerrado nativo $(\mathrm{CN})$ : área sob vegetação de Cerrado stricto sensu, preservada e sem histórico de perturbação antrópica. Esta área foi escolhida como referência para comparação das alterações dos atributos de QS; (b) pastagem natural (PN): área com vegetação de Cerrado stricto sensu, sendo utilizada há cerca de 15 anos como pasto para bovinos, sem controle de lotação; (c) pastagem plantada (PP): área onde foi implantada pastagem da espécie Brachiaria decumbens Stalf, implantada há cerca de 10 anos, sendo manejada com bovinos e sem controle de lotação. À época da implantação da pastagem, a acidez do solo foi corrigida com calcário incorporado com arado de disco; (d) cultivo convencional (CC): área em utilização para produção de grãos, principalmente de milho, submetida anualmente a preparo convencional, com aração e gradagem. Nesta área tem sido realizada calagem para atingir saturação por bases de $40 \%$ e, antes de cada plantio, é realizada adubação; e (e) florestamento de pínus (FP): área de florestamento com indivíduos adultos de Pínus elliottii Engelm, implantada há cerca de 20 anos, sem adubação ou tratos culturais. Uma serapilheira de acículas de pínus cobre todo o solo, com aproximadamente $4 \mathrm{~cm}$ de espessura.

\section{Atributos físicos de qualidade do solo}

Os indicadores quantificados foram: densidade do solo (Ds), porosidade total $(\mathrm{Pt})$, resistência mecânica à penetração vertical $(\mathrm{Rp})$ e taxa de infiltração de água (Ti).

Para determinação da Ds e da Pt, foram abertas três trincheiras, em cada área estudada. A densidade do solo foi obtida a partir de amostras indeformadas, com três repetições, coletadas nas profundidades de 0-5, 5-10, 10-20 e 20-30 cm, pelo método do anel volumétrico $\left(100 \mathrm{~cm}^{3}\right)$, e a densidade de partículas (Dp) foi determinada pelo método do balão volumétrico (Embrapa, 1997). A porosidade total (Pt) foi calculada por meio da relação existente entre a densidade do solo (Ds) e a densidade de partículas (Dp), conforme método descrito em Embrapa (1997).

A resistência mecânica à penetração vertical $(\mathrm{Rp})$ foi medida nas mesmas profundidades, utilizando-se um penetrômetro marca EIJKELKAMP, com diâmetro da ponteira de $1,5 \mathrm{~cm}$. Foram realizadas 15 repetições por área, e as medições foram executadas em solo úmido, no mesmo dia para todas as áreas, buscandose eliminar o efeito da variação da umidade do solo.

A taxa de infiltração foi avaliada em campo, com três repetições, utilizando-se dois anéis concêntricos, com 40 e $10 \mathrm{~cm}$ de diâmetro, introduzidos no solo verticalmente. A água foi mantida sob o mesmo nível durante o experimento, sendo o solo submetido à carga constante de $4 \mathrm{~cm}$ de coluna d'água (Reynolds et al., 1992).

\section{Atributos químicos de qualidade do solo}

Foram coletadas amostras deformadas, com três repetições, nas profundidades de $0-5,5-10,10-20$ e 20-30 cm.

O conteúdo de matéria orgânica (MOS) foi obtido pelo teor de $\mathrm{C}$ orgânico, determinado por oxidação via úmida, de acordo com método descrito em Embrapa (1997).

A capacidade de troca de cátions (CTC) também foi determinada por procedimentos extraídos da Embrapa (1997), sendo calculada pela soma dos valores obtidos para as bases trocáveis (S) e a acidez potencial $(\mathrm{H}+\mathrm{Al})$.

\section{Atributos biológicos de qualidade do solo}

A amostragem foi realizada com três repetições, apenas na profundidade de $0-5 \mathrm{~cm}$, por se considerar esta profundidade a mais representativa dos atributos biológicos em estudo. O C na biomassa microbiana (Cmic) foi avaliado pelo método da fumigação e incubação (Jenkinson \& Powlson, 1976).

A determinação da respiração basal (Rmic) foi feita nas mesmas amostras utilizadas para a primeira incubação e mediante titulação com solução de $\mathrm{HCl}$, ao final de sete dias de incubação.

\section{Análise estatística e modelagem}

A análise estatística dos resultados consistiu da análise da variância, segundo delineamento experimental inteiramente casualizado, incluindo-se a profundidade como subfator. Foi utilizado o teste de Tukey a $5 \%$ para comparação entre as médias dos atributos para as cinco glebas. Foram ainda estabelecidas correlações de Pearson entre os atributos estudados. 
A avaliação comparativa da qualidade do solo, nas áreas submetidas a diferentes usos, foi realizada mediante o emprego de um modelo baseado em Islam \& Weil (2000), com modificações. Para organização do modelo, foram adotadas as seguintes premissas: (a) os valores observados para os indicadores da qualidade do solo na área sob Cerrado nativo foram utilizados como referência, pois se trata de ecossistema em equilíbrio e estável; (b) as três categorias de atributos de qualidade do solo avaliados (físicos, químicos e biológicos) contribuem eqüitativamente para determinação da qualidade do solo, sendo atribuído a cada categoria o mesmo peso ponderado; $\mathrm{e}$ (c) dentro de cada categoria, os indicadores de qualidade do solo avaliados têm a mesma importância relativa.

Para elaboração de um modelo comparativo de qualidade do solo, os indicadores de qualidade de natureza física foram a densidade do solo, a resistência à penetração e a taxa de infiltração de água no solo; os de natureza química, os teores de matéria orgânica e a capacidade de troca catiônica; e os de natureza biológica, o $\mathrm{C}$ da biomassa microbiana e a respiração basal.

O cálculo da qualidade do solo foi realizado separadamente para cada área ou gleba sob diferente uso, atribuindo-se um valor de $100 \%$ para cada categoria de atributos. Dentro de cada categoria, esse percentual foi dividido uniformemente para cada indicador utilizado. Na avaliação da contribuição do valor de cada indicador, foi calculada a soma da percentagem dos desvios de cada indicador em relação ao valor obtido para o solo da área de referência.

Nos casos em que o aumento no valor numérico do atributo é indesejável (Ds e Rp), valores maiores do que o da área de referência foram considerados negativos para qualidade do solo. Por exemplo, se o valor de Ds para o solo da área de referência for de $0,8 \mathrm{~kg} \mathrm{dm}^{-3} \mathrm{e}$, para o da área em avaliação, de $1,2 \mathrm{~kg} \mathrm{dm}^{-3}$, significa que houve redução de 50 \% na qualidade para esse indicador.

Para cada área ou gleba avaliada foi calculado um valor percentual, agregando os dados individuais dos indicadores adotados nas três categorias de atributos (físicos, químicos e biológicos); esses valores foram plotados em diagrama com três eixos, um para cada categoria. Para área de referência (Cerrado nativo) foi predefinido um percentual de $100 \%$, para cada uma das categorias de atributos.

O índice de qualidade do solo (IQS) para cada gleba avaliada foi então calculado, comparando-se a dimensão (área geométrica) do triângulo resultante para cada gleba com a do resultante para a gleba de Cerrado nativo.

\section{RESULTADOS E DISCUSSÃO}

\section{Atributos físicos de qualidade do solo}

Os dados obtidos para densidade do solo e porosidade total (Quadro 1) demonstram haver variação significativa entre as áreas avaliadas, especialmente na camada superficial $(0-5 \mathrm{~cm})$. Tendo como referência o solo sob Cerrado nativo $(\mathrm{CN})$, verifica-se nesta profundidade, que os valores mais altos para a Ds e, conseqüentemente, mais baixos para $\mathrm{Pt}$ foram registrados nas áreas sob pastagem plantada e cultivo convencional. Contudo, não foram observadas diferenças significativas entre as profundidades para uma mesma área, indicando que os efeitos do uso foram similares até a profundidade de $30 \mathrm{~cm}$ (Quadro 1).

Os valores mais elevados de Ds registrados nas áreas sob pastagem plantada (PP) e cultivo convencional (CC) podem ser resultantes do pisoteio dos animais e trânsito de máquinas e implementos, respectivamente. Kondo \& Dias Junior (1999) demonstraram que o efeito do pisoteio do gado em pastagens ocorre principalmente nos primeiros centímetros do solo, cerca de $0-3 \mathrm{~cm}$; entretanto, o adensamento ocorreu ao longo de toda a camada estudada.

Os valores de Ds, em todas as áreas estudadas (Quadro 1), encontram-se abaixo daqueles relatados como limitantes ou com potencial de causar dificuldades ao crescimento radicular e, conseqüentemente, ao pleno desenvolvimento das culturas (Camargo \& Alleoni, 1997).

Como a porosidade é a proporção do volume do solo que não é ocupada por partículas sólidas e esse espaço poroso é por onde a água e o ar fluem, é esperado que nos solos sob CC e PP a água drene com maior dificuldade e as raízes das plantas encontrem maior resistência ao seu crescimento.

Os valores observados de porosidade total para as áreas sob cultivo convencional (CC), Cerrado nativo $(\mathrm{CN})$ e pastagem plantada (PP) são similares aos relatados em trabalhos publicados por Secco et al. (1997), Kondo \& Dias Junior (1999), Silva et al. (2000) e Beutler et al. (2001).

Em termos gerais, observa-se que as áreas com maior intensidade de uso do solo (PP e CC) apresentam maiores valores de Ds e menores de Pt (Quadro 1).

Os dados obtidos para a resistência mecânica à penetração vertical (Rp), apresentados no quadro 1 , também mostram diferenças entre as diversas áreas e profundidades, e as maiores diferenças ocorreram na camada de 0 a $5 \mathrm{~cm}$, ficando ainda melhor evidenciado o efeito dos tipos de uso a que o solo está submetido nas propriedades do solo. Nesta camada, o maior valor encontrado foi para o solo sob pastagem plantada (PP), confirmando o efeito do pisoteio dos animais no solo.

Comparando os valores de $\mathrm{Rp}$ em diferentes profundidades de solo, observa-se que nas áreas sob $\mathrm{PP}$ e CC houve maior resistência até a profundidade de $30 \mathrm{~cm}$. Por outro lado, os resultados para Cerrado nativo $(\mathrm{CN})$ e florestamento de pínus $(\mathrm{FP})$, são muito baixos, em todas as profundidades, refletindo o longo período em que esses solos permanecem sem sofrer processos de mobilização. 
Quadro 1. Médias de densidade do solo, porosidade total e resistência mecânica à penetração do solo, em áreas sob diferentes usos e profundidades, na Fazenda Água Limpa, DF

\begin{tabular}{|c|c|c|c|c|}
\hline \multirow{2}{*}{ Área } & \multicolumn{4}{|c|}{ Profundidade } \\
\hline & 0 a $5 \mathrm{~cm}$ & 5 a $10 \mathrm{~cm}$ & 10 a $20 \mathrm{~cm}$ & 20 a $30 \mathrm{~cm}$ \\
\hline & \multicolumn{4}{|c|}{ Densidade do solo, $\mathrm{kg} \mathrm{dm}^{-3}$} \\
\hline Cerrado Nativo & 0,75 aCD & 0,81 aA & 0,80 aAB & 0,83 aAB \\
\hline Pastagem Natural & 0,85 aBC & 0,78 aA & $0,75 \mathrm{aB}$ & 0,78 aB \\
\hline Pastagem Plantada & $1,05 \mathrm{aA}$ & 0,97 aA & $1,03 \mathrm{aA}$ & 1,01 aA \\
\hline Cultivo Convencional & 0,98 aAB & 0,95 aA & 0,91 aAB & 0,85 aAB \\
\hline \multirow[t]{2}{*}{ Florestamento de Pínus } & $0,67 \mathrm{aD}$ & 0,73 aA & $0,70 \mathrm{aB}$ & $0,75 \mathrm{aB}$ \\
\hline & \multicolumn{4}{|c|}{ Porosidade total, $\mathrm{m}^{3} \mathrm{~m}^{-3}$} \\
\hline Cerrado Nativo & 0,67 aAB & 0,65 aA & 0,65 aAB & 0,64 aAB \\
\hline Pastagem Natural & $0,63 \mathrm{aBC}$ & 0,67 aA & 0,68 aAB & 0,67 aA \\
\hline Pastagem Plantada & $0,55 \mathrm{aD}$ & 0,59 aA & $0,56 \mathrm{aB}$ & $0,57 \mathrm{aB}$ \\
\hline Cultivo Convencional & 0,60 a $\mathrm{CD}$ & 0,61 aA & $0,63 \mathrm{aAB}$ & 0,65 a $\mathrm{AB}$ \\
\hline \multirow[t]{2}{*}{ Florestamento de Pínus } & 0,72 aA & 0,69 aA & 0,71 aA & 0,69 aA \\
\hline & \multicolumn{4}{|c|}{ Resistência à penetração, $\mathrm{MPa}$} \\
\hline Cerrado Nativo & $0,19 \mathrm{cC}$ & $0,24 \mathrm{bcC}$ & $0,30 \mathrm{abBC}$ & $0,32 \mathrm{aC}$ \\
\hline Pastagem Natural & $0,41 \mathrm{aB}$ & $0,40 \mathrm{aB}$ & $0,44 \mathrm{aB}$ & $0,44 \mathrm{aB}$ \\
\hline Pastagem Plantada & 0,91 aA & $0,65 \mathrm{bA}$ & $0,60 \mathrm{bA}$ & $0,61 \mathrm{bA}$ \\
\hline Cultivo Convencional & $0,49 \mathrm{bB}$ & $0,60 \mathrm{abA}$ & 0,69 aA & $0,61 \mathrm{abA}$ \\
\hline Florestamento de Pínus & $0,05 \mathrm{cD}$ & $0,15 \mathrm{bC}$ & $0,27 \mathrm{aC}$ & $0,32 \mathrm{aC}$ \\
\hline
\end{tabular}

Letras minúsculas comparam profundidades entre colunas. Letras maiúsculas comparam áreas entre linhas. Médias seguidas de mesma letra não diferem entre si pelo teste Tukey a $5 \%$.

Da mesma forma que para os atributos Ds e Pt, os valores de resistência à penetração evidenciam haver estreita relação com a intensidade de uso do solo, ou seja, quanto maior intensidade de uso, mais compactação, confirmando relatos de outros trabalhos (Secco et al., 1997; Beutler et al., 2001). Embora não haja consenso sobre os níveis críticos ou sustentáveis para esse atributo, refletindo sua variabilidade com relação às condições de umidade do solo e também a diversidade de procedimentos metodológicos, conforme discutido por Camargo \& Alleoni (1997), pode-se deduzir que nas áreas sob cultivo convencional e pastagem cultivada haverá prejuízo para o pleno desenvolvimento radicular e o aproveitamento do reservatório de água do solo pelas plantas.

Altas taxas de infiltração de água no solo foram registradas para as áreas de Cerrado nativo e de florestamento de pínus, com valores de 204 e $185 \mathrm{~cm} \mathrm{~h}^{-1}$, respectivamente. Esses valores foram estatisticamente superiores às taxas para as demais áreas, com apenas 5,7, 5,3 e 2,1 $\mathrm{cm} \mathrm{h}^{-1}$, respectivamente para pastagem natural, pastagem plantada e cultivo convencional.

Fabrício et al. (1999), apesar de registrarem valores de infiltração um pouco inferiores aos deste trabalho, em Latossolo Vermelho, verificaram também elevada diferença de infiltração de água no solo, entre uma área com vegetação natural e áreas de cultivo intensivo. Aguiar et al. (1999) relataram significativa redução da taxa de infiltração de água no solo sob cultivo convencional, da ordem de $78 \%$, em relação ao mesmo solo com vegetação de Cerrado.

É importante ressaltar a significativa diminuição da taxa de infiltração de água no solo em função da intensidade de uso. Os dados indicam que, quando áreas de Cerrado são utilizadas para pastagem de bovinos, sua taxa de infiltração diminui muito, atingindo valores próximos aos das áreas sob usos mais intensivos.

Considerando a grande extensão de pastagens naturais e plantadas na região do Cerrado e, ainda, que a maioria destas se encontra degradada ou em processo de degradação, é possível prever impactos significativos no fluxo e na qualidade dos recursos hídricos, tanto pela ação erosiva das enxurradas quanto pelo assoreamento e poluição dos reservatórios hídricos, resultantes da deposição dos sedimentos carreados pela enxurrada.

\section{Atributos químicos de qualidade do solo}

Para o atributo MOS, somente foram observadas diferenças significativas na camada de $0-5 \mathrm{~cm}$, sendo os valores mais elevados registrados para as áreas de pastagens e Cerrado, ficando a de florestamento de pínus (FP) num patamar intermediário e a de cultivo convencional (CC) com os menores valores (Quadro 2). 
Quadro 2. Teores de matéria orgânica e de capacidade de troca catiônica (CTC) do solo em áreas sob diferentes usos e profundidades, na Fazenda Água Limpa, DF

\begin{tabular}{|c|c|c|c|c|}
\hline \multirow{2}{*}{ Área } & \multicolumn{4}{|c|}{ Profundidade } \\
\hline & 0 a $5 \mathrm{~cm}$ & 5 a $10 \mathrm{~cm}$ & 10 a $20 \mathrm{~cm}$ & 20 a $30 \mathrm{~cm}$ \\
\hline & \multicolumn{4}{|c|}{ Matéria orgânica, g kg-1 } \\
\hline Cerrado Nativo & $45,2 \mathrm{aAB}$ & $37,7 \mathrm{bA}$ & $37,1 \mathrm{bA}$ & $35,4 \mathrm{bA}$ \\
\hline Pastagem Natural & 48,8 aA & $37,7 \mathrm{bA}$ & $30,7 \mathrm{bcA}$ & $28,3 \mathrm{cA}$ \\
\hline Pastagem Plantada & 47,3 aA & 37,4 abA & $36,9 \mathrm{abA}$ & $30,4 \mathrm{bA}$ \\
\hline Cultivo Convencional & $31,7 \mathrm{aC}$ & 34,3 aA & 34,5 aA & 32,7 aA \\
\hline \multirow[t]{2}{*}{ Florestamento de Pínus } & 38,5 aBC & 33,4 abA & $31,3 \mathrm{bA}$ & $30,1 \mathrm{bA}$ \\
\hline & \multicolumn{4}{|c|}{$\mathrm{CTC}, \mathrm{cmol}_{\mathrm{c}} \mathrm{dm}^{-3}$} \\
\hline Cerrado Nativo & 11,12 aA & $8,36 \mathrm{bA}$ & $7,44 \mathrm{bcA}$ & $5,96 \mathrm{cAB}$ \\
\hline Pastagem Natural & 10,12 aA & $6,63 \mathrm{bB}$ & $5,68 \mathrm{bcB}$ & $5,30 \mathrm{cAB}$ \\
\hline Pastagem Plantada & 8,21 aB & $6,76 \mathrm{bB}$ & $6,00 \mathrm{bcB}$ & $5,14 \mathrm{cAB}$ \\
\hline Cultivo Convencional & 7,40 aB & 7,41 aAB & $6,94 \mathrm{aAB}$ & $6,53 \mathrm{aA}$ \\
\hline Florestamento de Pínus & $7,77 \mathrm{aB}$ & $6,71 \mathrm{abB}$ & $5,85 \mathrm{bcB}$ & $5,38 \mathrm{cAB}$ \\
\hline
\end{tabular}
mesma letra não diferem entre si pelo teste Tukey a $5 \%$.

Possivelmente, essa superioridade se deve ao predomínio de gramíneas na área sob pastagem plantada e à diversidade e quantidade de vegetação na pastagem natural e no Cerrado nativo, que proporcionam um maior aporte de biomassa ao solo. Alvarenga \& Davide (1999) também constataram que áreas de pastagem não diferiram estatisticamente de áreas de Cerrado, indicando se tratar de um ambiente altamente conservador de matéria orgânica.

Já na área sob florestamento de pínus, apesar do grande volume de serapilheira, o teor de MOS é baixo, provavelmente em razão da pequena superfície específica externa das acículas e da alta relação C:N desses resíduos. Zinn (1998), em estudo com florestamento de pínus, também verificou reduções significativas dos teores de MO, comparado à área de Cerrado nativo, na profundidade de 0 a $5 \mathrm{~cm}$, não sendo observadas diferenças nas profundidades subjacentes.

Os baixos valores de MOS encontrados para a área sob cultivo convencional (Quadro 2) devem ser reflexo do revolvimento contínuo do solo, que favorece a decomposição do material orgânico, além do pequeno aporte de resíduos vegetais durante a condução da cultura, conforme observado por Seguy et al. (1984).

Os resultados encontrados para a capacidade de troca catiônica (CTC) mostram tendências similares às da MOS, com valores superiores para as áreas de Cerrado nativo e pastagem natural, na camada superior (Quadro 2). Foi observada significativa redução da CTC em relação à profundidade, sendo a área sob cultivo convencional a única que não mostrou alterações significativas entre as profundidades, possivelmente devido à homogeneização das camadas pelo revolvimento anual do solo.

\section{Atributos biológicos de qualidade do solo}

Os resultados obtidos para o $\mathrm{C}$ da biomassa microbiana (Cmic) evidenciaram superioridade do Cerrado nativo em relação às demais áreas (Quadro 3), apesar de não ser estatisticamente diferente da área sob pastagem plantada, onde foi observado intenso desenvolvimento radicular das gramíneas forrageiras na camada superior do solo, possivelmente favorecendo a atividade biológica, refletida pelo alto valor de respiração basal (Rmic).

D'Andréa et al. (2002), em experimento conduzido em Latossolo Vermelho distrófico argiloso, na profundidade de 0 a $5 \mathrm{~cm}$, sob áreas de Cerrado,

Quadro 3. Teores de carbono da biomassa microbiana (Cmic) e respiração basal do solo (Rmic), na camada de 0-5 cm, em áreas sob diferentes usos, na Fazenda Água Limpa, DF

\begin{tabular}{lcc}
\hline \multicolumn{1}{c}{ Área } & \multicolumn{1}{c}{ Cmic } & Rmic \\
\hline & $\mathrm{mg} \mathrm{kg}^{-1}$ & $\mathrm{mg} \mathrm{kg}^{-1} \mathrm{dia}^{-1}$ \\
Cerrado Nativo & $532,07 \mathrm{~A}$ & $13,14 \mathrm{~B}$ \\
Pastagem Natural & $235,83 \mathrm{BC}$ & $14,57 \mathrm{~B}$ \\
Pastagem Plantada & $400,79 \mathrm{AB}$ & $21,37 \mathrm{~A}$ \\
Cultivo Convencional & $309,63 \mathrm{~B}$ & $8,86 \mathrm{C}$ \\
Florestamento de Pínus & $106,34 \mathrm{C}$ & $8,51 \mathrm{C}$
\end{tabular}

$\overline{\text { Letras maiúsculas comparam colunas. Médias seguidas de }}$ mesma letra não diferem entre si pelo teste Tukey a $5 \%$. 
pastagem e plantio convencional, obtiveram valores de Cmic bem superiores aos encontrados neste trabalho, sendo verificada, no entanto, a mesma tendência decrescente nos valores de Cmic das áreas $\mathrm{CN}$ para aquelas sob CC.

\section{Relações entre os atributos de qualidade do solo}

A análise de correlação entre os atributos avaliados mostrou correlação significativa, simples e direta, entre os seguintes atributos: Ds x Rp, Rp x Rmic, MOS x CTC e MOS x Rmic. Adicionalmente, verificouse haver correlação significativa, simples e indireta, entre Ds x Ti e Rp x Ti.

As correlações entre os atributos de natureza física eram esperadas, pois o aumento na densidade do solo é reflexo de processo de adensamento e, ou, compactação do solo, resultando em aumento da resistência mecânica à penetração, o qual, por sua vez, diminui a permeabilidade do solo e sua taxa de infiltração de água.

A correlação positiva da MOS com a CTC também é esperada, já que em solos tropicais, com predominância de argilominerais de baixa atividade, a fração orgânica contribui com a maior proporção das cargas negativas, confirmando relatos de Silva \& Resck (1997).

Apesar de a atividade da biota do solo ser limitada pela quantidade de substrato carbonado, observou-se não haver correlação da Rmic com o Cmic e sim entre os dados da Rmic e os da MOS, demonstrando que, independentemente dos teores de $\mathrm{C}$ da biomassa microbiana, existe relação estreita entre a matéria orgânica e a atividade dos microrganismos do solo. Observação similar foi relatada por Mendes \& Vivaldi (2001) em Latossolo Vermelho sob Cerrado.

\section{Modelo comparativo e índice de qualidade do solo}

A aplicação do modelo de qualidade do solo adotado, para as áreas estudadas, é sintetizada na figura 1.

$\mathrm{Na}$ avaliação da QS para a área sob pastagem natural (PN), é possível observar que os atributos biológicos e químicos são pouco modificados (Figura 1a), em contraste com os atributos físicos, que são altamente impactados. O índice de qualidade do solo (IQS) calculado para a $\mathrm{PN}$ foi de 0,54 , indicando redução de qualidade do solo de $46 \%$ em relação à área de Cerrado nativo.
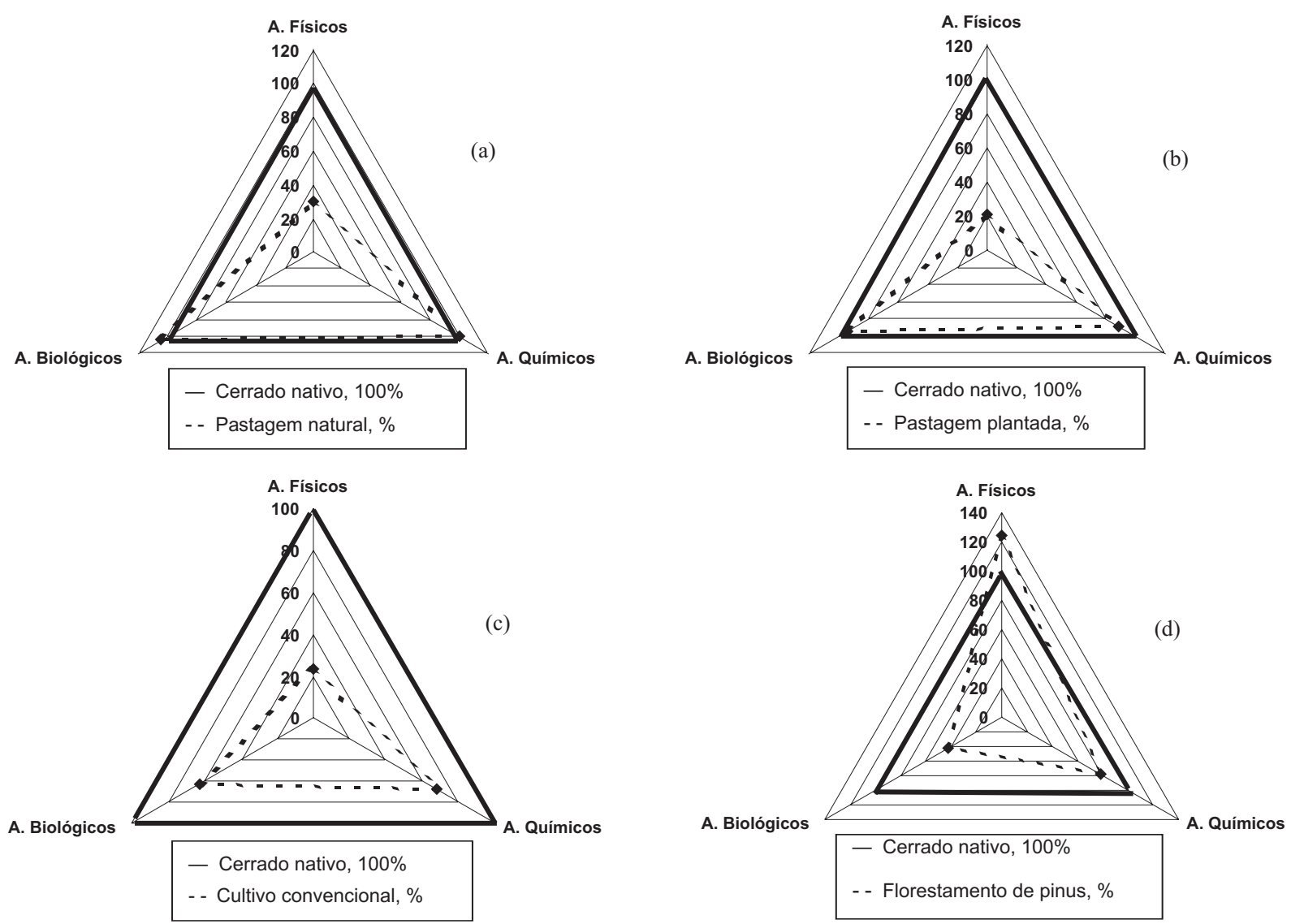

Figura 1. Diagramas comparativos da qualidade do solo, distribuída em atributos físicos, químicos e biológicos, em relação ao Cerrado nativo, considerando apenas a camada de 0 a $5 \mathrm{~cm}$ das seguintes áreas: (a) pastagem natural, (b) pastagem plantada, (c) cultivo convencional e (d) florestamento de pínus. 
O diagrama para a área sob pastagem plantada (PP) - figura $1 b$ - mostra características próximas às apresentadas pela área sob pastagem natural $(\mathrm{PN})$, com os atributos químicos e biológicos bem preservados e os físicos muito alterados, sendo, entretanto, os valores encontrados para a área PP um pouco inferiores. O valor do IQS calculado para essa área foi de 0,39 , indicando maior redução de qualidade do solo quando comparado à área $\mathrm{PN}$, possivelmente em razão do uso mais intensivo para pastejo.

Analisando o diagrama comparativo de qualidade do solo para área sob cultivo convencional (CC), exposto na Figura 1c, observa-se redução expressiva nas três categorias de atributos avaliados. $\mathrm{O}$ valor obtido para o IQS foi de apenas 0,23 , representando redução de 77 \% na qualidade do solo dessa área, certamente como resultante da elevada mobilização do solo e de seu manejo inadequado.

Os dados obtidos para a área sob florestamento de pínus (FP) mostram que esse uso, ao contrário dos outros, contribuiu para melhoria das propriedades físicas do solo (Figura 1d). Esse resultado possivelmente é um reflexo da não-mobilização do solo e da manutenção de uma camada de serapilheira sobre sua superfície. Com relação aos parâmetros biológicos, foi detectada expressiva redução quando comparada à área sob Cerrado nativo, possivelmente resultante da ação de substâncias inibidoras da decomposição dos resíduos orgânicos, contidas nas acículas do pínus, e da alta relação C:N desses resíduos. O valor de IQS calculado para essa área foi de 0,51 , indicando que esse tipo de uso também pode impactar negativamente a qualidade intrínseca do solo, apesar da melhoria nos seus atributos físicos e da excelente cobertura da superfície do terreno, protegendo o solo da ação erosiva da chuva e do vento.

Numa análise conjunta e agregada de todas as informações coletadas neste trabalho, observa-se relação estreita e inversa entre a intensidade de uso do solo e de sua qualidade. Observa-se ainda que os efeitos na qualidade são mais pronunciados na camada de 0 a $5 \mathrm{~cm}$.

Os atributos físicos de qualidade do solo foram os mais afetados pelos tipos de usos PN, $\mathrm{PP} \mathrm{e} \mathrm{CC}$ avaliados, como reflexo, principalmente, da compactação do solo e da diminuição da taxa de infiltração de água. Esses efeitos repercutem negativamente na resistência do solo à ação dos agentes erosivos e na função do solo como filtro da água de reposição do lençol freático, resultando em impactos negativos ao meio ambiente.

Entre os atributos físicos testados, a resistência mecânica à penetração vertical refletiu com nitidez as diferenças de QS entre as áreas avaliadas, sendo uma propriedade de fácil e rápida quantificação em campo. Contudo, para ser válida, requer teores similares de umidade do solo nas áreas a serem comparadas.
Dessa forma, a Rp poderá se constituir em importante indicador da qualidade do solo, tanto para estimar, preliminarmente, o grau de sustentabilidade das atividades agrossilvopastoris quanto para quantificar danos ao meio ambiente, mediante perícias judiciais, laudos ambientais ou atividades de fiscalização.

Os sistemas de uso e manejo de uma área têm grande influência sobre os atributos físicos de qualidade do solo, especialmente nas camadas mais superficiais, onde a compressão mecânica parece ser mais atuante. Klein \& Libardi (2002), ao avaliarem um solo submetido a diferentes manejos, também observaram alterações na sua estrutura, com aumento da densidade e redução da porosidade total, com conseqüente diminuição da condutividade hidráulica, estabelecendo relação entre a degradação da qualidade e a intensidade de uso do solo.

Em trabalho sobre sustentabilidade de agroecossistemas, Alvarenga \& Davide (1999), comparando ambientes de Cerrado, pastagem natural, pastagem plantada com 10 anos de uso, culturas anuais e reflorestamentos de eucalipto com um e 15 anos, também observaram que o agrossistema com culturas anuais foi o que se apresentou mais alterado no que diz respeito às características físicas do solo, demonstrando, de maneira geral, degradação da sua qualidade.

Tendo em vista não haver ainda consenso sobre a interpretação dos valores para os indicadores biológicos avaliados, é necessário cautela quando esses atributos são utilizados para estimar a qualidade do solo. Assim, por exemplo, alta atividade microbiana não é necessariamente indicativo de melhoria na qualidade do solo, podendo inclusive ser considerada um fator negativo, em virtude de acelerar a decomposição dos resíduos orgânicos e, portanto, diminuir o tempo de residência da matéria orgânica no solo.

O modelo comparativo utilizado mostrou-se útil para uma avaliação integrada da qualidade do solo e para estimar o efeito de tipos de usos a que um solo é submetido. Ademais, auxilia na tarefa de discriminar a contribuição relativa de cada atributo no processo de modificação da qualidade do solo.

Para uma avaliação ambiental, com ênfase no fluxo de água no solo, poderiam ser utilizados somente indicadores de natureza física, juntamente com o teor de matéria orgânica, atributo estreitamente relacionado ao estado de qualidade de um solo.

O índice IQS considera a contribuição interativa de todos os atributos, fornecendo uma avaliação abrangente da qualidade do solo. Com base nesse índice, pôde-se constatar que as quatro áreas avaliadas mostraram expressivas perdas de qualidade do solo, especialmente quando em sistema de cultivo convencional. Assim como a maioria dos atributos individuais, o IQS refletiu uma relação estreita entre a qualidade do solo e a intensidade de uso. 


\section{CONCLUSÕES}

1. De modo geral, os atributos físicos, químicos e biológicos do solo foram afetados em função dos tipos de uso das áreas.

2. O uso intensivo do solo contribui para redução da sua qualidade em relação ao solo sob Cerrado nativo.

3. Os indicadores de natureza física foram os que melhor refletiram as diferenças de qualidade do solo entre as áreas avaliadas.

4. O índice de qualidade do solo (IQS), obtido a partir do diagrama comparativo, permite distinguir ambientes sob diferentes usos, sendo recomendável na avaliação de impactos ambientais.

5. Os valores do IQS calculados para as áreas avaliadas estão assim ordenados: Cerrado nativo $>$ pastagem natural $>$ florestamento de pínus $>$ pastagem plantada $>$ cultivo convencional.

\section{LITERATURA CITADA}

AGUIAR, A.V.; ALVES, M.C.; SASSAKI, N. \& BORTOLOZO, F.R. Taxa de infiltração e algumas propriedades físicas de um Latossolo Vermelho-Escuro sob diferentes sistemas de manejo. In: CONGRESSO BRASILEIRO DE CIÊNCIA DO SOLO, 27., Brasília,1999. Anais. Brasília, Sociedade Brasileira de Ciência do Solo/Embrapa, 1999. CD-ROM

ALVARENGA, M.I.N. \& DAVIDE, A.C. Características físicas e químicas de um Latossolo Vermelho-Escuro e a sustentabilidade de agrossistemas. R. Bras. Ci. Solo, 23:933-942, 1999.

BEUTLER, A.N.; SILVA, M.L.N.; CURI, N.; FERREIRA, M.M.; CRUZ, J.C. \& PEREIRA FILHO, I.A. Resistência à penetração e permeabilidade de Latossolo Vermelho distrófico típico sob sistemas de manejo na região dos Cerrados. R. Bras. Ci. Solo, 25:167-177, 2001.

CAMARGO, O.A. \& ALLEONI, L.R.F. Compactação do solo e o desenvolvimento das plantas. Piracicaba, Escola Superior de Agricultura Luiz de Queiroz, 1997. 132p.

D’ANDRÉA, A.F.; SILVA, M.L.N.; CURI, N.; SIQUEIRA, J.O. \& CARNEIRO, M.A.C. Atributos biológicos indicadores da qualidade do solo em sistemas de manejo na região do Cerrado no sul do estado de Goiás. R. Bras. Ci. Solo, 26:913-923, 2002.

DORAN, J.W. \& PARKIN, T.B. Defining and assessing soil quality. In: DORAN, J.W. \& COEMAN, D.C.; BEZDICEK, D.F \& STEWART, B.A., eds. Defining soil quality for sustainable environment. Madison, Soil Science Society of America, 1994. p.3-21. (SSSA Special Publication, 35)

EMPRESA BRASILEIRA DE PESQUISA AGROPECUÁRIA EMBRAPA. Centro Nacional de Pesquisa de Solos. Manual de métodos de análise de solo. 2.ed. Rio de Janeiro, 1997. 212 p.
EMPRESA BRASILEIRA DE PESQUISA AGROPECUÁRIA EMBRAPA. Centro Nacional de Pesquisa de Solos. Sistema brasileiro de classificação de solos. Rio de Janeiro, 1999. 412p.

FABRÍCIO, A.C.; CUNHA, T.J.F.; FREITAS, P.L. \& MARTINS, J.S. Modificações morfoestruturais de solo sob Cerrado, decorrentes de diferentes sistemas de manejo em Chapadão do Sul-MS. In: CONGRESSO BRASILEIRO DE CIÊNCIA DO SOLO, 27., Brasília, 1999. Anais. Brasília, Sociedade Brasileira de Ciência do Solo/Embrapa, 1999. CD ROM

ISLAM, K.R. \& WEIL, R.R. Land use effects on soil quality in a tropical forest ecosystem of Bangladesh. Agric. Ecosys. Environ., 79:9-16, 2000.

JENKINSON, D.S. \& POWLSON, D.S. The effects of biocidal treatments on metabolism in soil-V. A method for measuring soil biomass. Soil Biol. Biochem., 8: 209-213, 1976.

KLEIN, V.A. \& LIBARDI, P.L. Condutividade hidráulica de um Latossolo Roxo, não saturado, sob diferentes sistemas de uso e manejo. Ci. Rural, 32:120-128, 2002.

KONDO, M.K. \& DIAS JUNIOR, M.S. Compressibilidade de três Latossolos em função da umidade e uso. R. Bras. Ci. Solo, 23:211-218, 1999.

MENDES, I.C. \& VIVALDI, L.A. Dinâmica da biomassa e atividade microbiana em uma área sob mata de Galeria na região do Distrito Federal. In: RIBEIRO, J.F.; FONSECA, C.E.L. \& SOUZA-SILVA, J.C., eds. Cerrado, caracterização e recuperação de Matas de Galeria. Planaltina, Embrapa - CPAC, 2001. p.665-687.

REYNOLDS, W.D.; VIEIRA, S.R. \& TOPP, G.C. An assessment of the single-head analysis for the constant head well permeameter. Can. J. Soil Sci., 72:489-501, 1992.

SANTANA, D.P. \& BAHIA FILHO, A.C. Qualidade do solo: Uma visão holística. B. Inf. SBCS, 27:15-18, 2002.

SECCO, D.; DA ROS, C.O.; FIORIN, J.E.; PAUTZ, C.V. \& PASA, L. Efeito de sistemas de manejo nas propriedades físicas de um Latossolo Vermelho-Escuro. Ci. Rural, 27:5760, 1997.

SEGUY, L.; KLUTHCOUSKI, J.; SILVA, J.G.; BLUMENSCHEIN, F.N. \& DALL'ACQUA, F.M. Técnicas de preparo do solo: Efeitos na fertilidade e na conservação do solo, nas ervas daninhas e na conservação de água. Goiânia, Embrapa - CNPAF, 1984. 26p.

SILVA, J.E. \& RESCK, D.V.S. Matéria orgânica do solo In: VARGAS, M.A.T. \& HUNGRIA, M., eds. Biologia dos solos dos cerrados. Planaltina, Embrapa, 1997. p.465-524.

SILVA, M.L.N.; CURI, N. \& BLANCANEAUX, P. Sistemas de manejo e qualidade estrutural de Latossolo Roxo. Pesq. Agropec. Bras., 35:2485-2492, 2000. 
TÓTOLA, M.R. \& CHAER, G.M. Microrganismos e processos microbiológicos como indicadores da qualidade dos solos. In: ALVAREZ V, V.H.; SCHAEFER, C.E.G.R.; BARROS, N.F.; MELLO, J.W.V. \& COSTA, L.M., eds. Tópicos em ciência do solo. Viçosa, MG, Sociedade Brasileira de Ciência do Solo. 2002. v.2. p.196-276.
ZINN, Y.L. Caracterização de propriedades físicas, químicas e da matéria orgânica de solos nos cerrados sob plantações de Eucalyptus e Pinus. Brasília, Universidade de Brasília, 1998. 85p. (Tese de Mestrado) 